\title{
REMINERALIZATION OF ENAMEL SURFACE IN SITU BY NANO-CHITOSAN HYDROXYAPATITE
}

\author{
BATUBARA FY ${ }^{1}$, TRIMURNI ABIDIN ${ }^{2}$, HARRY AGUSNAR ${ }^{3}$ \\ ${ }^{1,2}$ Research Scholar, Department Conservative Dentistry, Faculty of Dentistry, Universitas Sumatera Utara, Medan, Indonesia \\ ${ }^{3}$ Research Scholar, Department of Chemical Science, Faculty of Mathematics and Natural Sciences, Universitas Sumatera
}

Utara, Medan, Indonesia

\begin{abstract}
The process of caries begins with hard tissue demineralization by organic acids produced from fermented carbohydrates by cariogenic bacteria in dental plaque. Remineralization is a slow process compared to demineralizationso that the provision of remineralization material is needed to reduce the demineralization process. This research aims to compare the effect of hydroxyapatite and nano-chitosan hydroxyapatite gel in reducing enamel demineralization by using SEMEDX to find the amount of content (weight \%) of calcium phosphorus and morphological changes of enamel surface of enamel.

Twenty four recently extracted embedded molar teeth enamel were used and divided into four groups. Group I was only immersed in clarified saliva. Group II immersed in ademineralization solution for four days. Group III immersed indemineralization solution for four days and then are applied with hydroxyapatite gel. Group IV immersed in demineralization solution for four days then given a combination of nano-chitosan hydroxyapatite gel.

Statistical tests showed no significant difference in the amount of calcium and phosphorus between the email that was applied with hydroxyapatite gel and nano-chitosan hydroxyapatite gel (p-value >0.05). Qualitative analysis using SEM shows that there is a change in the surface morphology of tooth enamel which shows the decrease in demineralization after application of hydroxyapatite gel and nano-chitosan hydroxyapatite gel. In conclusion, hydroxyapatite gel and nano-chitosan hydroxyapatite gel have the same ability to reduce the demineralization process of tooth enamel.
\end{abstract}

KEYWORDS: Email Demineralization, Hydroxyapatite, Nano-Chitosan Hydroxyapatite

Received: Jun 06, 2020; Accepted: Jun 26, 2020; Published: Jun 30, 2020; Paper Id.: IJMPERDJUN2020145

\section{INTRODUCTION}

Dental caries is a pathological process of localized tooth tissue damage. This disease begins with the demineralization of hard tooth tissue by organic acids produced from carbohydrates that can be fermented by cariogenic bacteria in dental plaque. Frequent exposure to foods containing fermentable carbohydrates, especially foods that contain sugar will cause an increase in cariogenic bacterial populations such as Streptococcus mutans, Lactobacillus spp., and other species in the biofilm layer. These bacteria are acidogenic and aciduric which produce organic acids, especially lactic acid and actively produce these acids at $\mathrm{pH}$ values around $5 .{ }^{1}$

The $\mathrm{pH}$ value is a critical $\mathrm{pH}$ value for enamel apatite which will cause damage. The critical $\mathrm{pH}$ value is considered as the highest $\mathrm{pH}$ value where tooth enamel will experience mineral loss. The true value depends on the activity of $\mathrm{Ca}^{2+}$ and $\mathrm{PO}_{4}{ }^{3}$ ions on the hydration layer around the enamel crystals and this is usually balanced by the 
same concentration of ions in the salivary fluid and plaque. Laboratory research results state that the critical $\mathrm{pH}$ of tooth enamel is around 5.5. This is based on the average $\mathrm{Ca}^{2+}$ and $\mathrm{PO}_{4}{ }^{3-}$ concentrations in salivary fluid and plaque. ${ }^{1}$

During the caries process, most organic acids produced by plaque bacteria are not in a separate form. The organic acid will diffuse into the tooth enamel through the water-filled interprismatic space so that the $\mathrm{pH}$ in the hydration layer around the enamel crystal becomes lower. If the $\mathrm{pH}$ is below 5.5, the crystalline enamel will experience mineral loss in a process called. ${ }^{1}$

The pathophysiology of caries is highly dependent on the components of dental minerals, especially calcium and phosphate, which are demineralized and released by organic acids which are the product of bacterial production, which is in biofilms, attached to the surface. Calcium and phosphate ions are released from the enamel subsurface, causing initial lesions to form in the enamel. ${ }^{2}$ These initial lesions are reversible because with the remineralization process, calcium and phosphate ions are supplied from external sources to the teeth to stimulate ion deposits into the crystal cavities which has been formed at the time of demineralization to produce minerals again. The ability of remineralization in teeth that have undergone demineralization is very dependent on the condition of the oral cavity, including saliva, individual diets, and habits of patients, especially in maintaining the cleanliness and health of their teeth and mouth. ${ }^{3}$

In laboratory studies, experimental animals and in situ caries models in humans it appears that Casein Phosphopeptide-Amorphous Calcium Phosphate (CPP-ACP) has anticariogenic activity. CPP can stabilize calcium phosphate in solution with the residual phosphoserine so that the formation of CPP-ACP bonds. ${ }^{1} \mathrm{CPP}-\mathrm{ACP}$ as remineralization material still has weaknesses. CPP-ACP has low solubility in acidic conditions. This will reduce the ability of CPP-ACP to hold calcium and phosphate ions in an acidic environment.

The use of natural products in the field of dentistry is currently growing rapidly. This research will use high molecular chitosan and hydroxyapatite from marketed pearl shells.

Chitosan is one of the biomaterials that lately continues to be developed because it has various medical benefits and is proven safe for humans. Chitosan has special properties, including good biocompatibility, biodegradable, non-toxic, does not cause immunological reactions, does not cause cancer. With the special nature of chitosan, chitosan and modifications with other materials can be used for clinical applications as biomaterials.

Arnaud et al. (2010) investigated the effects of chitosan on the demineralization and remineralization processes of tooth enamel associated with the presence of phosphorus. The results of the study concluded that chitosan plays a role in the remineralization process by inhibiting the release of phosphorus from tooth enamel. ${ }^{4}$

Chitosan can also interact with metal ions. The interaction of chitosan with metal ions occurs because of the complexing process where ion exchange, absorption, and chelating occur. ${ }^{5}$

Calcium and phosphorus are the main minerals that makeup bones and teeth. Among calcium phosphate salts, hydroxyapatite is the most similar one to the mineral parts in bones and teeth. Hydroxyapatite is a form that describes a bond containing calcium ions which can be combined with orthophosphate, phyrofosfat, hydrogen or hydroxide which is the main ingredient in the formation of bone and tooth enamel, called bio-material. ${ }^{6}$ This substance has high biocompatible properties and has been used in medical treatment widely. The purpose of this study is to determine the effect of nanochitosan when added to hydroxyapatite, can it reduce the surface demineralization process of tooth enamel. 


\section{MATERIALS AND METHODS}

\section{Preparation of 2\% Hydroxyapatite Gel}

Hydroxyapatite gel is made by dissolving 2 grams of hydroxyapatite obtained fromcommercial hydroxyapatite, added with $100 \mathrm{ml}$ of aquabidest then the solution is sterilized with Jar Test at a speed of $200 \mathrm{rpm}$ for \pm 30 minutes so that a homogeneous gel is obtained.

\section{Preparation of Hydroxyapatite Nano-Chitosan Gel}

Chitosan gel was prepared by dissolving 1 gram of chitosan in $50 \mathrm{ml}$ of a weak acid solution (1\% acetic acid) and then sterilized with a Jar Test at $200 \mathrm{rpm}$ so that the gel was obtained for \pm 30 minutes. Then the chitosan solution was dropped with a solution of 20 drops of sodium tripolyphosphate (NaTPP0.5\%) as much as 20 drops while slowly sterilizing. Mix the chitosan solution with sodium tripolyphosphate again with jartest for \pm 30 minutes. The addition of $0.5 \%$ NaTPP was done so that the surface of the solution was smooth. The solution that has formed the gel is inserted into the ultrasonicbath to break the chitosan particles into nano. Nano chitosan is filtered and the residue is washed with aquadest. The resulting residue in the form of nano chitosan gel will be added to the hydroxyapatite.

As much as $25 \mathrm{~mL}$ of nano chitosan solution was added to $25 \mathrm{~mL}$ of $2 \%$ hydroxyapatite solution slowly while stirring until homogeneous. To achieve a neutral solution, $0.05 \mathrm{M} \mathrm{NaOH}$ is added until the $\mathrm{pH}$ reaches 7 , which is seen with Universal $\mathrm{pH}$.

\section{Preparation of Research Saliva (Lemos et al., 2010)}

\section{Preparation of the Adsorption Buffer Solution}

The adsorption buffer solution was prepared with a mixture of $50 \mathrm{mM} \mathrm{KCl} ; 1 \mathrm{mM}$ potassium phosphate $\left(0.35 \mathrm{mM} \mathrm{K}_{2} \mathrm{HPO}_{4}\right.$ plus $\left.0.65 \mathrm{mM} \mathrm{KH}_{2} \mathrm{PO}_{4}\right) ; 1 \mathrm{mM} \mathrm{CaCl}_{2} ; 0.1 \mathrm{mM} \mathrm{MgCl}$. The $\mathrm{pH}$ value is equal to 6.5. The solution is stored at room temperature.

\section{Saliva Preparation (Clarified Saliva)}

$50 \mathrm{~mL}$ of saliva was collected from one donor. Saliva is mixed with an adsorption buffer solution (ratio 1: 1, v / v) and added with $50 \mu \mathrm{L} 0.1 \mathrm{M}$ phenylmethyl-sulfonyl fluoride (PMSF). The mixture of the solution was centrifuged at 5,500g; $4^{\circ} \mathrm{C}$ for 10 minutes. Supranatant was taken and filtered with a $0.22 \mu \mathrm{m}$ PES low protein binding-filter.

\section{Sample Preparation}

This study used six molar teeth. The root of the tooth is cut using a disc bur with water spray. Each tooth will be cut into four parts in the mesiodistal and bucolingual / bukopalatal direction so that 24 sample pieces will be obtained which will be divided into four groups. The buccal / lingual part is planted in a 3cc syringe which is cut to a height of $1 \mathrm{~cm}$ using acrylic resin and an open area with a diameter of about $2 \times 2 \mathrm{~mm}$ is obtained. 


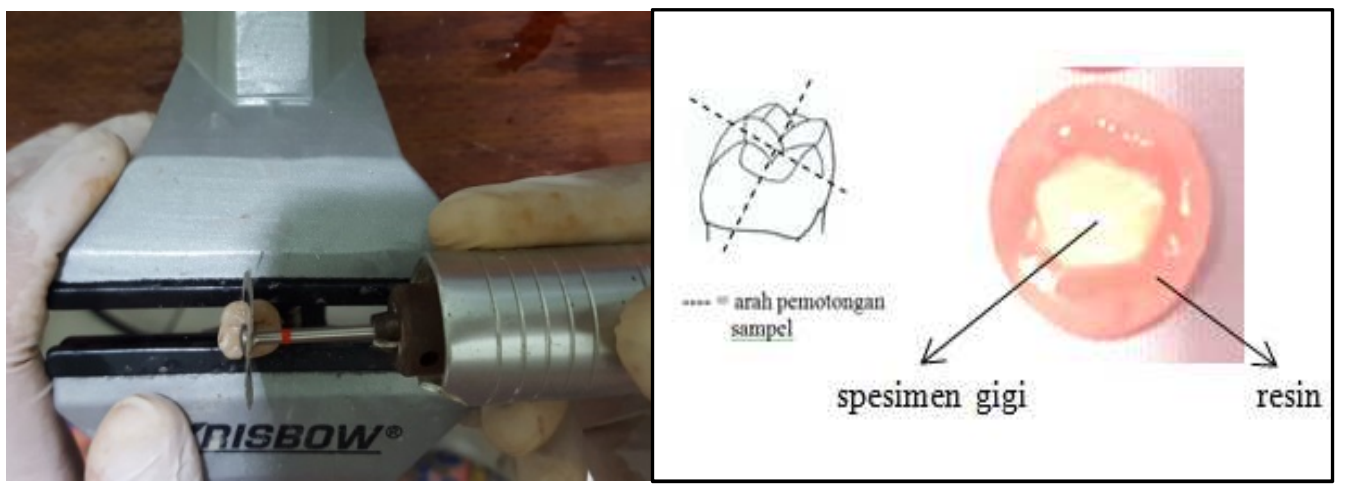

Figure 1: Sample Preparation (A) Preparation of Sampleprocedures; (B). Sketch of the Direction of Cutting the Sample and the Sample to be Treated and Tested.

\section{Sample Treatment and Testing}

The samples are numbered 1 to 24 and divided randomly into four groups so that each group consists of six samples. The sample was conditioned as if in the oral cavity by soaking the clarified saliva for 24 hours. The treatment for each group modified from the research conducted by Hedge and Moany (2012) is as follows:

- Group I was only soaked in clarified saliva and incubated in an incubator shaker at $37^{\circ} \mathrm{C}$ for seven days.

- Group II soaked in the demineralization solution for four days. Then the sample was immersed with clarified saliva and incubated in an incubator shaker at $37^{\circ} \mathrm{C}$ for seven days.

- Group III soaked in the demineralization solution for four days and then given a hydroxyapatite gel once a day for five minutes. Then the sample was immersed in clarified saliva and incubated in an incubator shaker at $37^{\circ} \mathrm{C}$ for seven days.

- Group IV soaked in the demineralization solution for four days then given a nano-chitosan hydroxyapatite combination gel once a day for five minutes. Then the sample was immersed in clarified saliva and incubated in an incubator shaker at $37^{\circ} \mathrm{C}$ for seven days.

All samples were given thermocycling treatment on the seventh day. Thermocycling was carried out as many as 500 cycles using $5^{\circ} \mathrm{C}$ and $55^{\circ} \mathrm{C}$ temperatures. Sample testing with SEM-EDX was carried out on the eighth day. Testing the sample with EDX aims to find out the ratio of\% by weight of the elements Ca and P in each group. While the SEM examination aims to obtain a microstructure description of the sample.

\section{DATA ANALYSIS}

The data obtained was performed one-way analysis of variance statistical tests (ANOVA) with a significance level ( $\alpha=$ 0.05) to determine differences in remineralization of email in groups I, II, III, and IV. Then a Post HocLeast Significant Difference (LSD) test was performed to determine the difference in the reduction in email demineralization between the treatment groups. 


\section{RESULTS}

\section{Chemical Elements on the Email Surface of Each Group}

The content of elements on the email surface of each group is known by observation through EDX. Email each treatment group contains elements of carbon $(\mathrm{C})$, nitrogen $(\mathrm{N})$, oxygen $(\mathrm{O})$, phosphorus $(\mathrm{P})$, and calcium (Ca). Descriptive data of the elements contained in the emails of each treatment group can be seen in Table 1.

Table 1: Descriptive Data Showing Mean Values and Standard Deviations of Chemical Elements Contained in the Emails of each Treatment Group

\begin{tabular}{|c|c|c|c|c|c|}
\hline \multirow{2}{*}{ Group } & $\mathbf{C}(\%$ Weight $)$ & $\begin{array}{c}\mathbf{N} \\
(\% \text { Weight })\end{array}$ & $\begin{array}{c}\text { O } \\
(\% \text { Weight })\end{array}$ & $\mathbf{P}(\%$ Weight $)$ & $\begin{array}{c}\text { CA (\% } \\
\text { Weight })\end{array}$ \\
\cline { 2 - 6 } & $\overline{\mathbf{X}} \pm$ SD & $\overline{\mathbf{X}} \pm$ SD & $\overline{\mathbf{X}} \pm$ SD & $\overline{\mathbf{X}} \pm$ SD & $\overline{\mathbf{X}} \pm$ SD \\
\hline I & $6,36 \pm 2,15$ & $17,23 \pm 3,33$ & $20,29 \pm 4,54$ & $19,20 \pm 0,65$ & $36,15 \pm 1,73$ \\
\hline II & $9,70 \pm 5,08$ & $17,92 \pm 3,23$ & $21,28 \pm 4,45$ & $17,63 \pm 0,64$ & $33,37 \pm 2,27$ \\
\hline III & $9,32 \pm 5,77$ & $17,54 \pm 4,48$ & $19,23 \pm 3,74$ & $18,59 \pm 0,86$ & $35,33 \pm 2,01$ \\
\hline IV & $6,58 \pm 1,00$ & $19,05 \pm 2,72$ & $19,25 \pm 3,65$ & $19,14 \pm 0,72$ & $35,98 \pm 1,91$ \\
\hline
\end{tabular}

I: groups that are only soaked in clarified saliva.

II: groups immersed in the demineralization solution.

III: immersed in the demineralized solution and then given a hydroxyapatite gel.

IV: immersed in the demineralization solution then given nano-chitosan hydroxyapatite combination gel.

\section{Content of Calcium (Ca) and Phosphorus (P) Element on the Email Surface of Each Group}

The results of observations with EDX obtained data content of elements of $\mathrm{Ca}$ and $\mathrm{P}$ in\% by weight. To find out the data obtained were normally distributed then the data normality test was first performed with the Shapiro-Wilk Test.

The test results showed all data content of $\mathrm{Ca}, \mathrm{P}$ and $\mathrm{Ca} / \mathrm{P}$ ratios in each group were normally distributed with $\mathrm{p}>$ 0.05. Homogeneity test results for all data variants showed a value of $p>0.05$ which means that the data variants were homogeneous.

Table 2 is a descriptive ANOVA test for the average content of $\mathrm{Ca}, \mathrm{P}$ and $\mathrm{Ca} / \mathrm{P}$ ratios with the calculation of the significance level $\alpha=0.05$. The results of the $\mathrm{Ca}$ element content test showed a $\mathrm{p}$ value $=0.048(\mathrm{p}-\mathrm{value}<0.05)$ statistically meaning there were significant differences in the amount of Ca element content among all treatment groups. The $\mathrm{P}$ element shows the value of $\mathrm{p}=0.004$ ( $\mathrm{p}$ - value $<0.05)$ which statistically also means that there are significant differences in the amount of $\mathrm{P}$ element content among all treatment groups. $\mathrm{Ca} / \mathrm{P}$ ratio shows the value of $\mathrm{p}=0.979$ ( $\mathrm{p}$ value> 0.05) statistically means there is no significant difference in $\mathrm{Ca} / \mathrm{P}$ ratio between all treatment groups.

Table 2: Descriptive Data Showing Mean Values and Standard Deviations from the ANOVA

Test in Testing the Amount of Calcium (Ca), Phosphorus (P), and CA / P Ratio on Enamel Surface of Each Group

\begin{tabular}{|c|c|c|c|c|c|c|}
\hline \multirow{2}{*}{ Group } & \multicolumn{2}{|c|}{$\begin{array}{l}\text { CA Element (\% } \\
\text { Weight) }\end{array}$} & \multicolumn{2}{|c|}{ P Element (\% Weight) } & \multicolumn{2}{|c|}{ CA/Prasio } \\
\hline & $\overline{\mathbf{X}} \pm$ SD & p value & $\overline{\mathbf{X}} \pm$ SD & p value & $\overline{\mathbf{X}} \pm$ SD & p value \\
\hline $\mathrm{I}$ & $36,15 \pm 1,73$ & \multirow{4}{*}{$0,048 *$} & $19,20 \pm 0,65$ & \multirow{4}{*}{$\mathbf{0 , 0 0 4 *}$} & $1,88 \pm 0,09$ & \multirow{4}{*}{0,979} \\
\hline II & $33,37 \pm 2,27$ & & $17,63 \pm 0,64$ & & $1,89 \pm 0,09$ & \\
\hline III & $35,33 \pm 2,01$ & & $18,59 \pm 0,86$ & & $1,90 \pm 0,95$ & \\
\hline IV & $35,98 \pm 1,91$ & & $19,14 \pm 0,72$ & & $1,88 \pm 0,89$ & \\
\hline
\end{tabular}


I: groups that are only soaked in clarified saliva.

II: groups immersed in the demineralization solution.

III: immersed in the demineralized solution and then given a hydroxyapatite gel.

IV: immersed in the demineralization solution then given nano-chitosan hydroxyapatite combination gel.

$* \mathrm{p}$ value $<0.05$ significant

Figure 2 shows descriptively the average amount of $\mathrm{Ca}, \mathrm{P}$, and $\mathrm{Ca} / \mathrm{P}$ ratio. The highest $\mathrm{Ca}$ element was seen in the sample group which was only immersed in clarified saliva and incubated in a shaker incubator at $37^{\circ} \mathrm{C}$ for 7 days (group I), while the mean value of the lowest amount of Ca element was seen in the group immersed in demineralization solution for four days, then immersed in clarified saliva, and incubated in an incubator shaker at $37^{\circ} \mathrm{C}$ for seven days (group II).

The highest average value of $\mathrm{P}$ content was seen in the sample group that was only immersed in clarified saliva and incubated in a shaker incubator at $37^{\circ} \mathrm{C}$ for 7 days (group I). The lowest mean value of $\mathrm{P}$ content was seen in groups immersed in demineralization solution for four days, soaked with clarified saliva, and incubated in an incubator shaker at $37^{\circ} \mathrm{C}$ for seven days (group II).

The highest average Ca / $\mathrm{P}$ ratio was seen in the sample group immersed in demineralization solution for four days and then given a hydroxyapatite gel once a day for five minutes, immersed in clarified saliva and incubated in an incubator shaker at $37^{\circ} \mathrm{C}$ for seven days (group III). The lowest average $\mathrm{Ca} / \mathrm{P}$ ratio was seen in the group immersed in demineralization solution for four days and then given a nano-chitosan hydroxyapatite combination gel once a day for five minutes, immersed in clarified saliva, and incubated in an incubator shaker at $37^{\circ} \mathrm{C}$ for seven days (group IV).

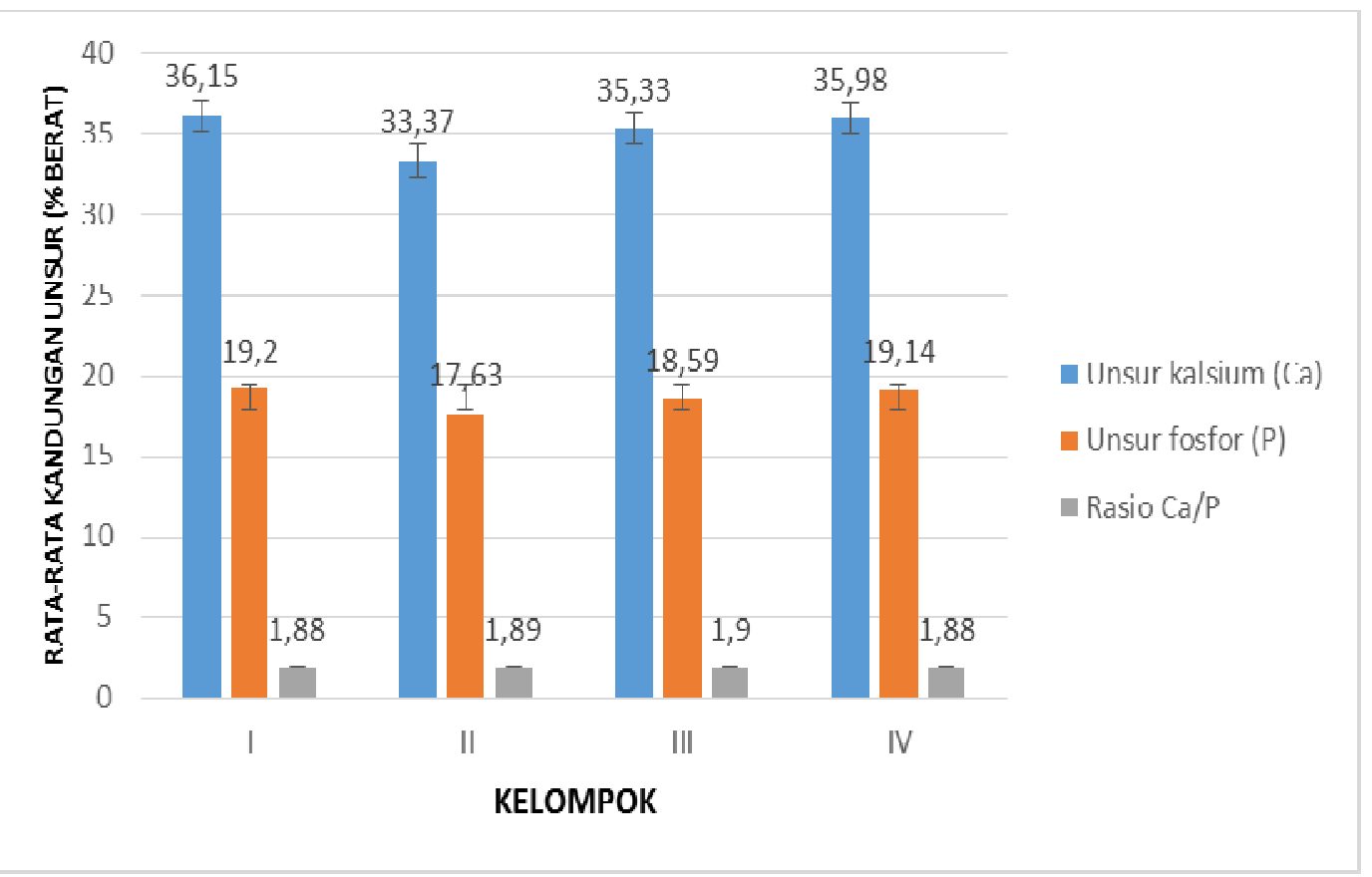

Figure 2: Graph of the Average Value of the Amount of Ca, P, and Ca / P Ratio after Treatment. 


\section{Effect of Given Hydroxyapatite Gel on the Content of Calcium and Phosphorus Email Surface}

To find out for certain groups that have different $\mathrm{Ca}, \mathrm{P}$, and $\mathrm{Ca} / \mathrm{P}$ ratios in the presence of hydroxyapatite gel, post hoc LSD testing was performed. The results of the post hoc LSD test in Table 3 show that the Ca element between groups I and III had a significant difference in content with a value of $\mathrm{p}=0.025$ ( $\mathrm{p}$ - value $<0.05$ ). Element $\mathrm{P}$ between groups II and III has a significant difference in content with a value of $\mathrm{p}=0.032$ ( $\mathrm{p}$ - value $<0.05$ ). The $\mathrm{Ca} / \mathrm{P}$ ratio did not show significant differences between any groups.

Table 3: Differences in the Content of Ca, P and Ca / P Ratios Between Each Group and Groups that Applied Hydroxyapatite Gel

\begin{tabular}{|c|c|c|c|c|}
\hline Element & Group & $\overline{\mathbf{X}} \pm \mathrm{SD}$ & Average Difference & p value \\
\hline \multirow{6}{*}{$\mathrm{Ca}$} & $\mathrm{I}$ & $36,15 \pm 1,73$ & \multirow{2}{*}{0,825} & \multirow{2}{*}{$0,025 *$} \\
\hline & III & $35,33 \pm 2,01$ & & \\
\hline & II & $33,37 \pm 2,27$ & \multirow{2}{*}{$-1,959$} & \multirow{2}{*}{0,103} \\
\hline & III & $35,33 \pm 2,01$ & & \\
\hline & IV & $35,98 \pm 1,91$ & \multirow{2}{*}{0,650} & \multirow{2}{*}{0,577} \\
\hline & III & $35,33 \pm 2,01$ & & \\
\hline \multirow{6}{*}{$\mathrm{P}$} & $\mathrm{I}$ & $19,20 \pm 0,65$ & \multirow{2}{*}{0,611} & \multirow{2}{*}{0,158} \\
\hline & III & $18,59 \pm 0,86$ & & \\
\hline & II & $17,63 \pm 0,64$ & \multirow{2}{*}{$-0,961$} & \multirow{2}{*}{$0,032 *$} \\
\hline & III & $18,59 \pm 0,86$ & & \\
\hline & IV & $19,14 \pm 0,72$ & \multirow{2}{*}{0,549} & \multirow{2}{*}{0,202} \\
\hline & III & $18,59 \pm 0,86$ & & \\
\hline \multirow{6}{*}{$\mathrm{Ca} / \mathrm{P}$ Element } & I & $1,88 \pm 0,09$ & \multirow{2}{*}{$-0,017$} & \multirow{2}{*}{0,740} \\
\hline & III & $1,90 \pm 0,95$ & & \\
\hline & II & $1,89 \pm 0,09$ & \multirow{2}{*}{$-0,009$} & \multirow{2}{*}{0,859} \\
\hline & III & $1,90 \pm 0,95$ & & \\
\hline & IV & $1,88 \pm 0,89$ & \multirow{2}{*}{$-0,021$} & \multirow{2}{*}{0,695} \\
\hline & III & $1,90 \pm 0,95$ & & \\
\hline
\end{tabular}

I: groups that are only soaked in clarified saliva.

II: groups immersed in the demineralization solution.

III: immersed in the demineralized solution and then given a hydroxyapatite gel.

IV: immersed in the demineralization solution then given nano-chitosan hydroxyapatite combination gel.

$* \mathrm{p}$ value $<0.05$ significant

\section{Effect on Addition of Hydroxyapatite Nano-Chitosan Gel to the Content of Calcium and Phosphorus Email Surface}

To find out for certain groups that have differences in the elemental content of $\mathrm{Ca}, \mathrm{P}$, and $\mathrm{Ca} / \mathrm{P}$ ratio with the addition of nano-chitosan hydroxyapatite gel, post hoc LSD testing was performed. The post hoc LSD test results in Table 4 show that the Ca elements in groups II and IV had significant differences in content with $\mathrm{p}$ values $=0.034(\mathrm{p}$ values $<0.05)$. The $\mathrm{P}$ element also shows a significant difference in content between groups II and IV. The Ca / P ratio did not show significant differences between any groups. 
Table 4: Differences In The Content Of Ca, P, And Ca / P Ratios Between Each Group And Groups That Applied Nano-Chitosan Hydroxyapatite Gel

\begin{tabular}{|c|c|c|c|c|}
\hline Element & Group & $\overline{\bar{X}} \pm$ SD & Average Difference & P Value \\
\hline \multirow{6}{*}{$\mathrm{Ca}$} & I & $36,15 \pm 1,73$ & \multirow[b]{2}{*}{0,174} & \multirow[b]{2}{*}{0,881} \\
\hline & IV & $35,98 \pm 1,91$ & & \\
\hline & II & $33,37 \pm 2,27$ & \multirow{2}{*}{$-2,609$} & \multirow{2}{*}{$0,034^{*}$} \\
\hline & IV & $35,98 \pm 1,91$ & & \\
\hline & III & $35,33 \pm 2,01$ & \multirow[b]{2}{*}{$-0,650$} & \multirow[b]{2}{*}{0,577} \\
\hline & IV & $35,98 \pm 1,91$ & & \\
\hline \multirow{6}{*}{$\mathrm{P}$} & I & $19,20 \pm 0,65$ & \multirow{2}{*}{0,062} & \multirow{2}{*}{0,883} \\
\hline & IV & $19,14 \pm 0,72$ & & \\
\hline & II & $17,63 \pm 0,64$ & \multirow{2}{*}{$-1,509$} & \multirow{2}{*}{$0,002 *$} \\
\hline & IV & $19,14 \pm 0,72$ & & \\
\hline & III & $18,59 \pm 0,86$ & \multirow{2}{*}{$-0,549$} & \multirow{2}{*}{0,202} \\
\hline & IV & $19,14 \pm 0,72$ & & \\
\hline \multirow{6}{*}{$\mathrm{Ca} / \mathrm{P}$ Element } & I & $1,88 \pm 0,09$ & \multirow{2}{*}{0,003} & \multirow{2}{*}{0,113} \\
\hline & IV & $1,88 \pm 0,89$ & & \\
\hline & II & $1,89 \pm 0,09$ & \multirow{2}{*}{0,012} & \multirow{2}{*}{0,830} \\
\hline & IV & $1,88 \pm 0,89$ & & \\
\hline & III & $1,90 \pm 0,95$ & \multirow{2}{*}{0,021} & \multirow{2}{*}{0,695} \\
\hline & IV & $1,88 \pm 0,89$ & & \\
\hline
\end{tabular}

I: groups that are only soaked in clarified saliva.

II: groups immersed in the demineralization solution.

III: immersed in the demineralized solution and then given a hydroxyapatite gel.

IV: immersed in the demineralization solution then given nano-chitosan hydroxyapatite gel.

$* \mathrm{p}$ value $<0.05$ significant

\section{Morphological Illustration of Each Group's Email Surface}

Observation of the surface morphology description of each treatment group (figure 3) was carried out using a Scanning Electron Microscope (SEM) tool. The e-mails observed in this study were e-mail surfaces that were clinically and microscopically intact and were not polished. Morphological description of tooth enamel seen in each group can be seen in table 5 .

Table 5: Morphological Depiction of Tooth Enamel seen in Each Group

\begin{tabular}{|l|l|}
\hline Group & \multicolumn{1}{|c|}{ Surface image of an email } \\
\hline I & $\begin{array}{l}\text { The surface of the enamel is uneven and smooth in the presence of enamel pores and uniform } \\
\text { aprismatic surface forms }\end{array}$ \\
\hline II & The surface of the enamel is rough and has porosity with a very large and irregular size \\
\hline III & $\begin{array}{l}\text { Rough surface of enamel with a smaller porosity size and more regular pore size of enamel from } \\
\text { demineralized email in group II }\end{array}$ \\
\hline IV & $\begin{array}{l}\text { The surface of the enamel is more subtle and the size of porosity is much less than demineralized } \\
\text { enamel in Group II }\end{array}$ \\
\hline
\end{tabular}




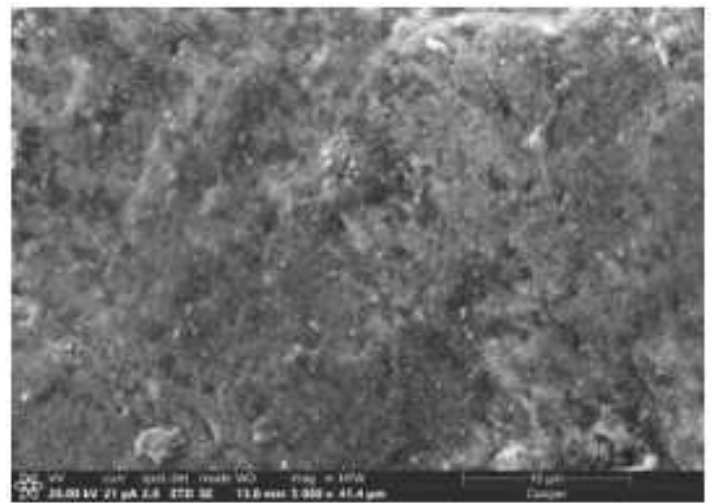

a)

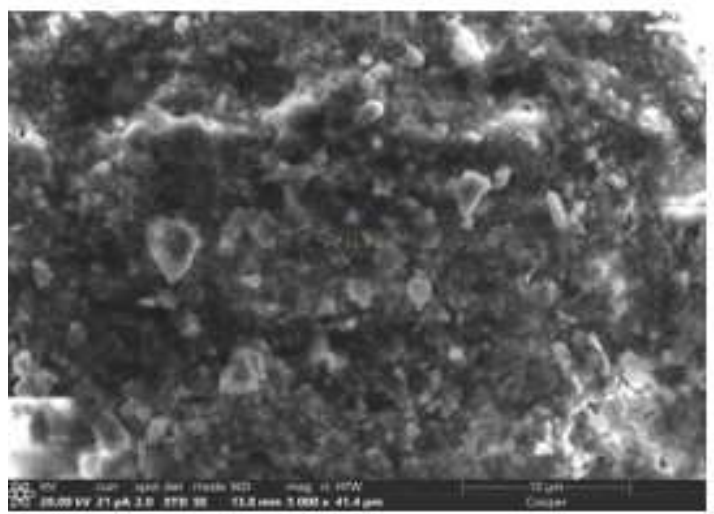

c)

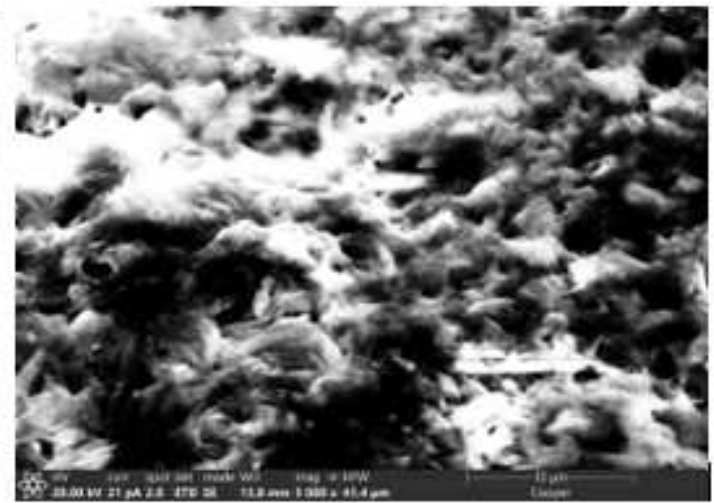

b)

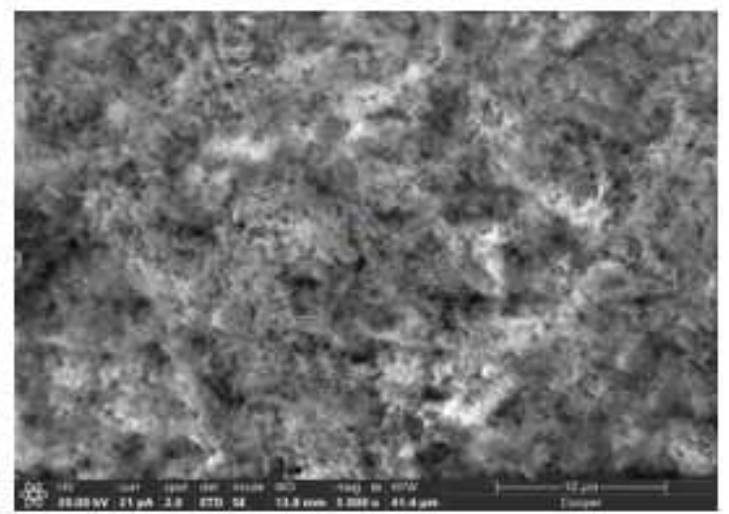

d)

Figure 3

Figure 3 Description of the surface morphology of the email. a) Emails that have only been soaked in clarified salivaand incubated in an incubator shaker at $37^{\circ} \mathrm{C}$ for seven days; b) Email that is only immersed in the demineralization solution for four days, then soaked with clarified saliva, and incubated in an incubator shaker at $37^{\circ} \mathrm{C}$ for seven days; c) Email were applied with the hydroxyapatite gel once a day for five minutes, immersed in clarified saliva, and incubated in an incubator shaker at $37^{\circ} \mathrm{C}$ for seven days; d) Emails were applied withnano-chitosan hydroxyapatite gel once a day for five minutes, soaked in clarified saliva, and incubated in an incubator shaker at $37^{\circ} \mathrm{C}$ for seven days (magnification of $5000 \mathrm{X})$.

\section{DISCUSSIONS}

The Effect on Addition of Hydroxyapatite Nano-Chitosan Gel on the Content of Calcium and Phosphorus Email Surface

Statistical analysis by post hoc LSD test showed that the calcium content of the sample group that was given demineralization treatment was then applied to nano-chitosan hydroxyapatite gel and the email sample group that was only given demineralization treatment had a significant difference with $\mathrm{p}=0.034(\mathrm{p}<0.05)$. Descriptively it was seen that the\% calcium weight of the group given demineralization treatment was then applied to nano-chitosan hydroxyapatite gel (35.98 $\pm 1.91)$ higher than the email sample group which was only given demineralization treatment $(33.37 \pm 2.27)$. 
The content of weight $\%$ phosphorus analyzed statistically by the post hoc LSD test showed a significant difference $\{p=0.002(p<0.05)\}$ between the email sample groups that were given demineralization treatment then the nano-chitosan hydroxyapatite gel was applied and the group that was only given demineralization treatment. Descriptively it was seen that the weight $\%$ of the elemental phosphorus group that was given demineralization treatment was then applied to nano-chitosan hydroxyapatite gel $(19.14 \pm 0.72)$ higher than the email sample group that was only given demineralization treatment $(17.63 \pm 0.64)$.

Statistical analysis with post hoc LSD test showed that the calcium element between the email sample groups that were given demineralization treatment then applied nano-chitosan hydroxyapatite gel with the group given demineralization treatment then given the application of hydroxyapatite gel did not have a significant difference $\mathrm{p}=0.577$ ( $p>0.05)$. Phosphorus content between the two groups also did not have significant differences with $\mathrm{p}=0.202(\mathrm{p}>0.05)$.

Descriptively it was seen that the email sample group which was given demineralization treatment then applied nano-chitosan hydroxyapatite gel containing calcium $(35.98 \pm 1.91)$ and phosphorus $(19.14 \pm 0.72)$ higher than calcium $(35,33 \pm 2.01)$ and phosphorus $(18.59 \pm 0.86)$ groups treated with demineralization were then given the application of hydroxyapatite gel.

Chitosan can absorb metals and form complex ions with metals. Chitosan as a cationic polymer can bind to metals where the amino groups contained in chitosan bind with metals and form covalent bonds. One of the forces acting on this bond is the Van der Walls force that is on the surface of the absorbent where there is a difference in energy or Van der Walls tensile strength between the absorbent and absorbate which causes the adsorbate to bind or be attracted to the adsorbent molecule. ${ }^{5}$

The addition of nano-chitosan to hydroxyapatite will accelerate the absorption of calcium which will be released at the time of demineralization. The amino group contained in chitosan will bind with calcium which will be released and form covalent bonds. The Van der Walls force that occurs between the chitosan amino group with calcium will cause calcium to be bound to the amino chitosan group. ${ }^{5}$ Thus the release of calcium from tooth enamel can be avoided and demineralization of tooth enamel will decrease.

The chitosan (-NH2) amino group in aqueous acid conditions will capture H+ from its environment so that its ammonia group is protonated to $-\mathrm{NH}_{3}+$. The positive charge $-\mathrm{NH} 3+$ can be used for adsorption of negatively charged substances (anionic). ${ }^{5}$ On the tooth surface the positive charge $-\mathrm{NH}_{3}+$ from chitosan can be utilized for the adsorption of negative substances in the form of $\mathrm{PO}_{4}$ - so that the phosphorus element is not separated from the enamel surface and the demineralization process can be inhibited.

The results of this study are in line with the research of Arnaud et al. (2010) who examined the effects of chitosan on the process of demineralization and remineralization of tooth enamel associated with the presence of phosphorus elements. ${ }^{4}$ The research shows that chitosan plays a role in the remineralization process by inhibiting the release of phosphorus from tooth enamel.

Chitosan used in this study had a degree of deacetylation of $84.20 \%$ with a molecular weight of $893,000 \mathrm{Mv}$. The degree of deacetylation plays an important role in the absorption process. Increasing the value of the degree of deacetylation causes an increase in the number of free amine groups. ${ }^{7}$ The molecular weight of chitosan and the degree of 
deacetylation can also facilitate solubility in acidic conditions and affect the absorption process. The increase in molecular weight and the degree of deacetylation of chitosan will affect the physical and physicoche.

The nanometer-scale chitosan particle size in this study will improve the efficiency of the physical-chemical process of chitosan surface with hydroxyapatite derived from calcium-rich pearl shells. Nano-chitosan hydroxyapatite gel in this studymore easily diffuse into the email prism which has a micrometer scale with a diameter of about 5-6 $\mu \mathrm{m}$. The size of the nanometer-scale chitosan particles will increase the surface area up to hundreds of times compared to micrometer-sized particles. This will increase the efficiency of the chitosan surface physics-chemical process, because it allows interaction on a larger surface. ${ }^{8}$

\section{Morphological Illustration of Each Group's Email Surface}

The email used in this study is the surface of email that is still intact macroscopically and not polished. The results of qualitative analysis using SEM obtained morphological description of each treatment group email.

Email groups that are only incubated in artificial saliva (Figure 5.2 a) show that the surface of the email is not completely flat and there is an email tip which is a normal variation of email.

Figure $3 \mathrm{~b}$ is a picture of email that has only been immersed in the demineralization solution. In demineralized enamel, porosity with irregular size and a bumpy surface indicates demineralization in tooth enamel.

Figure $3 \mathrm{c}$ is a picture of the surface of the enamel subjected to demineralization then the application of hydroxyapatite gel is given. In the picture we can see less porosity of email and smoother surface compared to email that only gets demineralized (Figure 5.2b). This shows that the hydroxyapatite gel from pearl shells in this study can inhibit the reduction of demineralization in tooth enamel with the penetration of calcium ions in demineralized enamel.

Figure $3 \mathrm{~d}$ is an image of the surface of the email applied to a combination of nano-chitosan hydroxyapatite gel. The surface of the email becomes smoother compared to email after the hydroxyapatite gel is applied (Figure 5.2b). This is thought to be related to the ability of chitosan in metal adsorption and the positive charge of $-\mathrm{NH}_{3}+$ from chitosan can be used for absorption of negatively charged substances. ${ }^{5}$ In this study, chitosan plays a role in the absorption of calcium and amino groups $\left(-\mathrm{NH}_{2}\right)$ chitosan which is protonated to $-\mathrm{NH}_{3}+$ under aqueous acid conditions it is thought to absorb negative ions in the form of $\mathrm{PO}^{4-}$ so that the phosphorus element cannot be separated from the tooth enamel surface. Besides, diffusion of nano-chitosan hydroxyapatite gel into enamel prisms which have a micrometer scale with a diameter of about 5-6 $\mu \mathrm{m}$ in this study will also facilitate gel diffusion so that deeper remineralization of enamel can occur.

The results of this study indicate that the hydroxyapatite gel and nano-chitosan hydroxyapatite gel can inhibit and reduce the demineralization process on the surface of tooth enamel. The reduction in enamel demineralization can be seen from the increase in calcium, phosphorus, the $\mathrm{Ca} / \mathrm{P}$ ratio in tooth enamel that can be detected by EDX, and the morphological picture of enamel seen through SEM.

\section{CONCLUSIONS}

Addition of nano-chitosan hydroxyapatite gel can reduce the process of demineralization of tooth enamel. There was no significant decrease in enamel demineralization between the hydroxyapatite gel and the nano-chitosan hydroxyapatite combination gel, as well as the release of calcium and phosphorus. The morphology of enamel surface in the application of hydroxyapatite gel and hydroxyapatite gel shows a different picture, where the administration of nano-chitosan 
hydroxyapatite gel shows the morphology of enamel surface morphology is much better than that applied by hydroxyapatite gel.

\section{ACKNOWLEDGEMENTS}

The authors would like to acknowledge Grant 31/UN5.2.3.1/PPM/KP-TALENTA USU/2019 from Lembaga Penelitian Universitas Sumatera Utara, Indonesia

\section{REFERENCES}

1 Reynolds EC, Walsh LJ., 2005. Additional Aids to the reminerational of tooth structure. In: Mount GJ, Hume WR. Australia: Knowledge books and software:111-8.

2 Jefferies SR., 2014. Advances in remineralization for early carious lesions: a comprehensive review. www. Compendiumlive.com. January 2014: 2-7.

3 Cochrane NJ, Cai F, Huq NL., et al. 2010. New approaches to enhance remineralization of tooth enamel. J Dent Res. 89(11) : 1187-97.

4 Arnaud TMS, Neto BDB, Diniz FB. 2010. Chitosan effect on dental enamel deremineralization: an in vitro evaluation. J Dent; 38: $8484-52$.

5 Sugita P, Wukirsari T, Sjahriza A, Wahyono D., 2009. Kitosan: sumber biomaterial masa depan. Bogor: IPB Press: 26,33,3.

6 Sadat-Shojai M, KhorasaniMT,Dinpanah-Khoshdargi E, Jamsidi A., 2013. Synthesis methods for nanosizedhydroxyapatite with diverse structures. Acta Biometer; 9(8):7591-62.

7 Susi KS., 2009. Pengaruhderajatdeasetilasinanokitosanuntukmenyerap ion $\mathrm{Zn}^{2+}$ darilimbahcair industry karet. Tesis. Medan. SekolahPascasarjanaUniversitas Sumatera Utara.

8 Tiyaboonchai W., 2003. Chitosan Nanoparticles: A Promising System for Drug Delivery. Naresuan University Journal; 11(3): 51-66.

9 Wadood, Sundus Abdul, Hussein Shatti Al-Essa, And Adil Galib Fadil. "Causes Of Teeth Extraction In Patients Attending The Outpatient Teaching Clinic In College Of Dentistry, University Of Basrah From 2012-2014." International Journal Of General Medicine And Pharmacy (Ijgmp) 5.6 (2016):27-34

10 Kumari, Purnima, Et Al. "In Vitro Callus Production And Anti-Bacterial Activity Of Barleria Prionitis Linn. Against Dental Caries Pathogens." International Journal Of Botany And Research (Ijbr) 3.4 (2013): 1-6.

11 Vj, Adarsh, Rosamma George, And G. Radha. "Evaluation Of Anti-Cariogenic Property Of Green Tea, Stabilized Chlorine Dioxide And Chlorhexidine By Assessing Its Effect On Ph Of Dental Plaque-A Randomized Clinical Trial." International Journal Of Dental Research \& Development (Ijdrd) 6.4 (2016):1-8 